\title{
Together we are more effective: Nursing team members' experiences of development work on patient education
}

\author{
Kaija Lipponen, Helvi Kyngäs, Outi Kanste \\ Institute of Health Sciences, University Hospital of Oulu, Finland
}

Correspondence: Kaija Lipponen. Address: Junnintie 49, 91410 J okirinne, Finland. Email: kaija.lipponen@oulu.fi.

Received: November 21, 2012

Accepted: January 3, 2013

URL: http://dx.doi.org/10.5430/jnep.v3n9p60

\begin{abstract}
Objective: Evaluating care pathways, strengthening patient education, developing staff's patient education skills, and improving collaboration between healthcare workers in hospitals and health centers are all topical challenges in the field of healthcare. Successful patient education requires seamless co-operation across organizational boundaries throughout the whole nursing process. The aim of this study was to assess personnel's experiences of a developmental nursing project, involving networking between Finnish primary (health centers) and special (hospitals) healthcare organizations, and the significance of development work on patient education in terms of strengthening information flow, co-operation and know-how. The aim of the study was to explore the healthcare personnel's experiences of development work in the context of networking between organizations, specifically focusing on the impact of development work with regard to information flow, co-operation and strengthening know-how. The specific research question was addressed: What is the impact of development work in this context in relation to information flow, co-operation and readiness for patient education?
\end{abstract}

Methods: Data were collected from theme interviews $(n=24)$ with primary and special healthcare team members who participated in a collaborative project, then analyzed by qualitative content analysis.

Results: The findings indicate that development work on patient education improves collective expertise, key components of which are learning as a patients' counselor, collective know-how, and the exchange of knowledge.

Conclusions: Development work can strengthen individual and collective know-how and nursing expertise. In the examined project, enhanced network co-operation increased collaboration between organizations and improved information flow throughout the nursing process. In addition, promotion of development on nursing and provision of feedback to the participants by the nurse manager appear to be crucial for successful development work on patient education. Workplaces and the nurse managers need to provide adequate resources' to develop nursing processes as well as motivate employees to improve nursing. Additionally, nurse managers should support and guide the healthcare workers in development work toward this goal. Well planned and executed development project can improve nursing practices across organizational boundaries.

\section{Key words}

Development work, Patient education, Collective expertise, Teamwork, Nursing collaboration 


\section{I ntroduction}

Patient education is an important aspect of nursing practice within both primary and special healthcare and is increasingly important as nursing hours decrease and patient empowerment increases. Innovative ways to develop patient education is needed in health care organizations today. In this study is using Finnish terms primary healthcare, which means care and nursing in health centers and special healthcare, which means care and nursing in hospitals.

Numerous studies ${ }^{[1,2]}$ have shown that successful patient education improves the compliance of patients and reduces hospital contacts after recovery, in addition to aiding patients to manage better at home. Enhancing patient education and support for patients' self-care, as routine components of long-term patients' care, can also improve continuity of care ${ }^{[3]}$. Thus, there is a clear need to assess patient education in healthcare organizations, and to develop, optimize and implement effective education practices. Successful patient education requires seamless co-operation between healthcare units throughout the whole service process, and the employment of similar educational practices by all nursing staff within a given healthcare network ${ }^{[4,5]}$. The continuity of treatment for patients with long-term illnesses is promoted including by patient-based operation, flawless information flow, well-founded treatment programs and recommendations as well as multidisciplinary co-operation and staff training ${ }^{[3,6]}$. Hence, evaluating care pathways, developing operation models, strengthening healthcare personnel's education skills, and enhancing co-operation between primary and special healthcare units, are all important aspects of development in the field of healthcare ${ }^{[5,7,9,15]}$.

The present study examines the impact of efforts to develop patient education regionally across organizational boundaries in a Finnish setting. The objectives of the development project were to strengthen staff's know-how regarding patient education, to establish common practices for patient education and to improve services, co-operation and information flow across the organizational boundaries. This development project was carried out through network co-operation involving healthcare staff working in multiprofessional teams, within both primary healthcare and hospitals, where self-determining, participative, supportive and co-operative strategies were applied. The central tenet of the network development project was that collaborative learning, involving groups of people working together to solve problems and create innovative practices, would help their organizations to run more smoothly and increase staff productivity.

The study presented here focused on employees operating as experts in their fields in six multidisciplinary teams engaged in a network development project. A team is a small group of people with complementary skills who work towards the same goal(s), have mutual models of objectives and operations, and share responsibility for their actions ${ }^{[8,9]}$. The deployment of such teams for service provision is both common and necessary in public health settings, because merging diverse skills, experience and know-how is essential for effective operation ${ }^{[10-12]}$. Accordingly, several studies have shown that efficient teamwork improves the quality of patient care and increases the work satisfaction of employees, giving them a chance to develop both their own work and the professional environment ${ }^{[13-15]}$.

Teams of professionals with abundant practical experience working within different stages of the care chain provide good foundations for co-operation ${ }^{[16]}$. However, common goals, internal interaction, community spirit and shared expertise are also crucial elements of successful network co-operation and teamwork ${ }^{[10,11,17]}$. When assessing the functionality of teamwork, attention must also be paid to aspects such as: team structure; the roles of team members; whether the operational culture promotes co-operation, trust and a positive team atmosphere; feedback practices; conflict resolution; sharing of information; multiprofessional learning; personal relationships; responsibility; commitment; interaction skills; functional skills; and problem-solving ${ }^{[8,9,12,15,18,19]}$.

The promotion of good communication pathways and co-operation between organizations within healthcare settings is highly important. Networks are good for producing, changing and interpreting and using information ${ }^{[5,20,21]}$. Trust and communication that create pleasure, facilitate co-operation and enhance the co-ordination of operations are also central in creating social capital. Social capital is also strongly related to the quality of patient care (and hence work satisfaction) and employee health ${ }^{[20]}$. 
The evaluation of one's own work, while challenging, presents staff with opportunities for occupational growth and learning ${ }^{[22-24]}$. Network development in the field of healthcare provides various kinds of learning and development possibilities ${ }^{[25,26]}$. The quality of clinical work can be improved by strengthening the skills of individual employees and the whole working community ${ }^{[7,27]}$. Work satisfaction, occupational growth and the improvement of staff expertise are beneficial for all those working within it and using its services ${ }^{[25,26,28]}$.

Network development in teams can aid the strengthening of staff's skills, by developing personal skills and co-operation within the network, and fostering occupational identity ${ }^{[9,29,30]}$. On an organizational level, knowledge strengthens communities' co-operation, problem-solving abilities and the discovery of new innovations. They also help to retain skilled employees within the organization. Furthermore, interaction and support are important in all team-based development work. Hence, peer development, support and teaching are key tasks of nurses ${ }^{[21,30]}$.

\section{Methods}

\subsection{Design}

The study was undertaken as part of a larger development project implemented in Northern Finland in 2006-2008. The objective of the project was to improve the quality of patient education and to increase the efficiency of co-operation between primary and special healthcare units regionally across organizational boundaries. Regional networking was implemented in six self-governing multidisciplinary teams of primary and special healthcare staff. The teams were formed to cater for the needs of six distinct patient groups (cardiovascular, cerebral infarction, COPD, cancer, total joint replacement and diabetic ulcer patients) that have high and frequent needs for the services of both primary and special healthcare units.

The aim of the study was to explore the healthcare personnel's experiences of development work in the context of networking between organizations, specifically focusing on the impact of development work with regard to information flow, co-operation and strengthening know-how. The specific research question was addressed: What is the impact of development work in this context in relation to information flow, co-operation and readiness for patient education?

\subsection{Data collection}

We collected data by interviews with the following themes: the significance, usefulness and impacts of the development work, and the health staff's experiences of participating in it. In addition, participants were asked to assess the effect of the development work on their own readiness to undertake patient education (with regard to knowledge, skills, attitude and education methods), information flow and co-operation. Participants were also asked to evaluate the general contribution of the project.

The interviews took place when the teams had nine months' experience of the development work. Participants consisted of members of network development teams $(n=24)$. We recruited participants discretionarily so that the group included representatives from each six teams and each occupational group (20 nurses working in special or in primary care, a public health nurse working in primary care, a practical nurse working in home care and two physiotherapists) as well as each municipality taking part in the development project $(n=14)$. All participants were actively involved in the development work and working within either primary $(n=15)$ or special $(n=9)$ healthcare. The age of the participants ranged from 24 to 53 years (mean $=40$ ) and all were women. Two men were involved in this development work but they did not wish to participate in the interviews.

The interview study followed the ethical principles of qualitative research. In Finland, ethical permission is not required in the interview surveys of personnel. In this study, participants gave their consent trough answering the questions. We contacted the discretionarily chosen team members via secure work e-mail addresses informing them of the purpose of the 
study and asking if they were interested in participating. The message explained the criteria for choosing the interviewees, listed the contact information of the researchers and offered the interviewees an opportunity to take part in the study. We clearly stated that participation in the study was voluntary and that any information they gave would be treated as confidential. Those who agreed to being interviewed contacted us through e-mail or by telephone. Interviews were carried out in the interviewees' workplace on convenient dates for them. The interview sessions lasted approximately an hour and were recorded. At the start of interviews, the participants were told about the recording procedure and were informed that no-one but the researchers doing the interviews would handle the recordings. Participants were given a piece of paper outlining the main themes of the interview with emphasis that there was no right or wrong answer. Participants were ensured of anonymity within the report. Thus, within this paper direct quotations are presented anonymously.

\subsection{Data analysis}

We analyzed the data using inductive content analysis. Interviews were first transcribed verbatim, producing 368 pages of text. The resultant text was then read several times by one researcher (KL). The same researcher (KL) analyzed data using inductive content analysis, which was followed by post analysis discussions to achieve consensus. This reinforced the validity of the research. We decided to use one complete thought expressed in one or a few sentences as an analysis unit. The analysis process proceeded from simplifying to grouping and abstracting ${ }^{[11,32]}$. All statements relating to a particular theme (designated subcategories, for example, the significance of development work and its impacts) were picked out, then grouped the subcategories into categories, each of which was given a descriptive name (learning as a patients' counselor, collective know-how and exchange of knowledge). Finally, we identified a single main category covering all the categories and descriptively named it 'collective expertise'. The analysis process is outlined in the Table 1.

Table 1. Sub-categories, categories and main category identified from the analysis of the interview transcripts

\begin{tabular}{lll}
\hline Sub-category & Category & Main category \\
\hline $\begin{array}{l}\text { Actual learning (knowledge, skills) } \\
\text { Changes in attitudes }\end{array}$ & Learning as a patients' counselor & \\
Opportunities to transfer individual & & \\
know-how & & Collective \\
Enhanced concept of patient education & & expertise related to development work \\
Expansion of overall picture & & on patient education \\
$\begin{array}{l}\text { Development in the project } \\
\text { Novel approach of working }\end{array}$ & Collective know-how & \\
Teamwork & & \\
$\begin{array}{l}\text { Equality in teams } \\
\text { Multiactor competence }\end{array}$ & & \\
$\begin{array}{l}\text { Scheduling } \\
\text { Distribution of work }\end{array}$ & & \\
Advantages of teamwork & & \\
Co-operation of primary and & & \\
special healthcare units & & \\
Occupational co-operation & Exchange of knowledge & \\
\hline
\end{tabular}

\section{Results}

\subsection{Learning as a patients' counselor}

Evidence of learning was identified in the participants' responses in terms of the development of knowledge and skills, changes in attitudes toward patient education and the behavior of counselors, and expansion of overall awareness of the nursing process. The development work appeared to have enhanced professionalism and the knowledge the participants 
gained strengthened their know-how. They reportedly received more up-to-date information on illnesses, and treatments, and were motivated to search for information. Involvement in the development work provided opportunities to assess update and deepen their own skills and knowledge.

"I've kind of come to the realization that education is constant and continuous."

Further, attitudes towards education became more positive as the project progressed. Participants saw value in their own know-how and considered it important to use it in development efforts and in the orientation of new employees. The concept of education also evolved during the development work. They increasingly regarded patient education as a dynamic process of planning, execution and evaluation, while viewing their individual roles in patients' care as elements of integrated care paths.

"I look for information much more actively. You pay more attention to whether the patient understands or not. You also think more about what your education practices are like."

Effects on the work unit were apparent through clearer multiprofessional co-operation, improvements in operational preparedness, a strengthened position of know-how and nursing and co-operation across operational sectors. The participants clearly regarded such co-operation (which includes active and interactive information sharing and a transition from working alone to co-operation for the good of patients) between all involved in a patient's care as highly beneficial for smooth operation.

"Contact is easier when there is a clear procedure on when to call the clinic or when to call the ward."

Staff received concrete tools and explicit instructions. The division of work was clarified and a lack of order gave way to clear operational models. Know-how was strengthened through direction, education, orientation and utilization of the development approach. Discussions within the participants' workplaces initiated idea-sharing and led to changes in operation.

"It's really the best thing that people talk about things. Then you really start thinking about why things are handled this way and whether they could be handled another way."

\subsection{Collective know-how}

Team members' experiences were that the efforts to enhance collective know-how included both development work in projects and work within multiple teams, which not only provided direct educational and positive experiences, but also resources through the gained experience for future development and project work.

"I have so much to give that I feel like I'm involved in the right project."

Collective factors had an impact on the successfulness of teamwork. A shared belief that the results of teamwork would be visible in the future, rather than simply being stored in files, enhanced team operation. Also, the identification of development needs from nursing practice, seeing the benefits and perceiving development work initiatives as a novel approach to work were considered having a positive impact on teamwork. The participants recognized that successful teamwork requires active participation, motivation, commitment, richness of ideas and a communicative, safe and good-humored atmosphere where everyone has a chance to be heard.

"The team is motivated and believes that this is an important project. Everyone has offered their opinion and all opinions have been taken into consideration..." 
In addition, the participants recognized that 'good chemistry' between the group members, mutual support, encouragement and collaborative enjoyment of achieved results across stages, enhanced teamwork. Individual differences and varied know-how within the team were found to be enriching. While strong personalities were needed, quieter personalities were also given room and their participation was supported. The experience of togetherness and the development of a shared language tightened the operation of the team. The composition of the team came to be one of the most important issues. The multiprofessional nature of the teams and the representation of different units in primary and special healthcare within them were of great importance. Interest in the work and roles of all participants, interest in the state of the municipalities and the ability to see broadly outside one’s own job and workplace also had a positive impact.

"It's very good that this is a combined primary and special healthcare project"

A focus on the teams' ability to work independently was characteristic of the development work. The participants found this independence confusing, and it slowed the initiation of team work, but independence also had positive elements. Challenges helped the teams to grow and tolerance of insecurity was a significant feature of the teams in the initial stages. As the work progressed, determination, the ability to set restrictions, and concrete targets, and a tenacious attitude supported the teamwork.

"I have positive feeling about the good progress of our work and positive feedback on our success."

The co-operation between primary and special healthcare teams was perceived as somewhat difficult at times. Occasionally, a 'them and us' mentality created a barrier between the individuals. Those working in special healthcare have the opportunity to focus on one thing at a time, which was seen as a benefit, whereas those working in primary care have to handle numerous at things at the same time. Where there was a lack of common understanding concerning development work or how ideas were to be implemented, teamwork was made more difficult. However, working on a familiar issue as an expert within multiprofessional team was found to be relatively easy. The operation was supported by the division of work and trust that everyone was doing their share. Also scheduling, regular meetings and altering meeting places had a positive impact on teamwork.

"We thought that if everyone plays their part and we discuss issues afterwards, we get things done more rapidly."

The size of teams was not of great significance and the varied age range was found to be enriching. Bigger teams had the benefit of an abundance of ideas and conversation. The division of work was also successful in bigger teams, and this was seen as a necessity for smooth operation.

" Even though the age range was so wide it didn't matter. Actually, it might have been a good thing."

Different roles and tasks within the teams affected the teams' operation. The role of team leader was central. Even team leaders had so-called weak moments but at those times, when it was considered necessary, another team member often put themselves forward. The activity of team members and the feeling of being the right person in the right place enhanced the success of the teams.

"Our team thinks that teamwork means sharing responsibility, but the team leaders are clearly holding the strings and that's strength in my opinion.”

\subsection{Exchange of knowledge}

The participants reported that the development work significantly improved their nursing. Expert roles and occupational identity were strengthened and networking was increased. The importance of written reports concerning treatment in transmitting information and avoiding duplication of effort was emphasized, and co-operation across operational sectors increased. 
Co-operation between primary and special healthcare units also improved. The relational closeness, manifested as familiarity and appreciation, provided sound foundations for co-operation and facilitated information flow. Though co-operation still had some shortcomings, conversation within groups was seen to increase awareness of problems and lead to positive changes.

"This creates the foundation for co-operation. Maybe we now have the tools for helping the information flow."

The organization of work by dividing staff into teams focusing on specific patient groups had a positive effect on the relationship between primary and specialist healthcare staff according to the participants. The continuity of care was believed to be improved, and a multidisciplinary approach was seen as a necessity. There was also a strong belief in different groups taking the same approach in the future.

"It's a great thing [for us, as continuing care workers] to know the guidelines in the university hospital and how we should then continue."

The development work also enhanced nursing through strengthening patients' trust in the staff by the provision of clear instructions, a consistent division of work within work communities and between organizations, and similar consistency in the approach to patient education.

"The information would be the same. The patient feels that people are informed and that information is passed on and not forgotten at any point."

Exchange of knowledge (including the effects of development work on occupational co-operation and co-operation between organizations) also increased, and the significance of co-operation became clearer as the project progressed. The development project provided resources to evaluate and enhance multiprofessional co-operation, and co-operation between different units within the workplace, raising awareness that there is no need for an individual (or specific unit) to do everything alone and highlighting possibilities to utilize the know-how of other occupational groups in learning situations. Relationships formed in the development work, and both the appreciation of other's work and the familiarity of content fostered partnership between primary and special healthcare units.

"You obtain a broader understanding of what others do and what you do."

\section{Discussion}

\subsection{Results}

The teams consisting of nursing personnel operating within different professions and stages of the patient's care pathway provided a good basis for the development work examined in this study. The participants' responses indicate that their perceptions were that patient education was enhanced, as studied previously ${ }^{[5,20,22]}$. Similarly, the exchange, gathering and sharing of implicit, explicit and cultural knowledge within the teams increased. This is significant since the utilization of expertise is important in the development of nursing ${ }^{[6,16,25,26]}$ as the combined knowledge, skills of co-operating team members inevitably exceeds their individual knowledge and skills. In addition to processing information, the participants indicated that multiprofessional learning, responsibility and commitment were central to good teamwork, again in accordance with previous findings ${ }^{[8,11,12,19]}$.

Members of each team had diverse types of know-how and responsibility, and tasks were shared ${ }^{[10,17]}$. The participants considered the team leaders (who were responsible for co-ordinating the development work in groups and summarizing the team's ideas) to be particularly important. They believed that the development work within teams strengthened the 
staff's abilities ${ }^{[18,29,30]}$, promoted occupational satisfaction through the development of their own work, in accordance with $^{[13,14]}$, and enhanced know-how, which is positively associated with staff support and treatment quality ${ }^{[23,24,28]}$. The teams provided space for learning and opportunities for staff to learn from fellow workers and share individual knowledge, which are highly important since previous authors ${ }^{[16,21,30]}$ have found that peer development, support and teaching are key tasks of nurses.

In addition to individual health personnel's expertise, the participants reported that collective expertise was enhanced by the improved network co-operation and flow of information between primary and special healthcare units. Partnership between multiple parties offered opportunities for mutual learning, chances for participants to learn within their own organization and within the operational area between organizations as previous studies have shown ${ }^{[5,7,9,20,27]}$. Team members experienced professional responsibility for the development of their education skills and thought it was important to implement results in nursing practice and reinforce co-operation between primary and special healthcare as well as think about the interest of patients. In addition, earlier studies ${ }^{[2-4]}$ have shown that training in patient education skills was important.

\subsection{Trustworthiness of the study}

We increased trustworthiness through the discretionary recruitment of participants, ensuring that they had sufficient knowledge of the research subject because they were all actively involved in the development work as team members. We carried out interviews in environments chosen by the participants and their involvement was voluntary. We attempted to identify the connections between the results, the interpretation and the material. To ensure trustworthiness, in this report we are using direct quotations (translated by KL) from interviews to support the interpretation of the researcher. The subjectivity of qualitative research limits the transferability of the results to other circumstances. Therefore, the results of this research can only be generalized to within the context of patient education development work. Nevertheless, interpretations may be applicable within similar contexts or to similar research subjects.

\subsection{Conclusion}

Development work improves individual and collective know-how and strengthens expertise in nursing. Development work should ideally be a component of routine work and it is important to recruit participants carefully to ensure that the initiation of development efforts is as smooth and unproblematic as possible.

Self-guided teamwork is challenging, but enables the utilization of every participant's know-how and innovative operation. Development of patient education through the co-operation of networks of primary and special healthcare units requires strong motivation, commitment, and the ability to work together, openness, mutual respect and interaction from the people involved.

Network co-operation offers occupational learning opportunities and both increases collaboration between organizations and improves the flow of information within nursing process. However, development work should not be the responsibility of employees alone. It requires support from colleagues and nurse managers, in the form of robust feedback and guidance to tackle difficulties. Also, the structures of development, particularly management and leadership, play a significant role in the success of development work. Nursing managers should ensure there are adequate resources to develop nursing processes as well as motivate employees to improve nursing. Well planned and executed network development can be recommended for use within development of nursing practices.

\section{Acknowledgements}

We wish to extend our thanks to the team members participating of this study. 


\section{References}

[1] Henderson A., Zernike W. A study of the impact of discharge information for surgical patients. J Adv Nurs. 2001; 35: 435-441. http://dx.doi.org/10.1046/j.1365-2648.2001.01857.x

[2] Johansson K., Salanterä S., Katajisto J. Empowering orthopaedic patients trough preadmission education: Results from a clinical study. Patient Educ Couns. 2007; 66: 84-91. http://dx.doi.org/10.1016/j.pec.2006.10.011

[3] Efraimsson E., Hillervik C., Ehrenberg A. Effects of COPD self-care management education at a nurse-led primary health care clinic. Scand J Caring Sci. 2008; 22: 178-185. http://dx.doi.org/10.1111/j.1471-6712.2007.00510.x

[4] Arranz P., Ulla SM., Ramos JL., del Rincon C., Lopez-Fando T. Evaluation of a counseling training program for nursing staff. Patient Educ Couns. 2005; 56: 233-239. http://dx.doi.org/10.1016/j.pec.2004.02.017

[5] Kerosuo H., Engeström Y. Boundary crossing and learning in creation of new work practice. Journal of Workplace Learning. 2003; 15: 345-351. http://dx.doi.org/10.1108/13665620310504837

[6] Ryan S., Hassel A., Thwaites C., Manley K., Home D. Developing a new model of care for patients with chronic musculoskeletal pain. J Nursing Manag. 2007; 15: 825-829. http://dx.doi.org/10.1111/j.1365-2934.2007.00761.x

[7] Ahgren B., Axelsson R. Determinants of integrated health care development: chains of care in Sweden. The international Journal of Health Planning and Management. 2007; 22: 145-157. http://dx.doi.org/10.1002/hpm.870

[8] Silen-Lipponen M, Tossavainen K, Turunen H, Smith A. Potential errors and their prevention in operating room teamwork as experienced by Finnish, British and American nurses. International Journal of Nursing Practice. 2005; 11: 21-32. http://dx.doi.org/10.1111/j.1440-172X.2005.00494.x

[9] Ratcheva V. Integating diverse knowledge through boundary spanning processes - The case of multidisciplinary project teams. Int J Project Manag. 2009; 27: 206-215. http://dx.doi.org/10.1016/j.ijproman.2008.02.008

[10] Thylefors I., Persson O., Hellström D. Team types, perceived efficiency and team climate in Swedish cross-professional teamwork. Journal of Interprofessional Care.2005; 19: 102-114. http://dx.doi.org/10.1080/13561820400024159

[11] Baker DP., Day R., Salas E. Teamwork as an essential component of high-reliability organizations. Health Services Research. 2006; 41:1576-1598. http://dx.doi.org/10.1111/j.1475-6773.2006.00566.x

[12] Kvarnström S., Cedersund E. Discursive patterns in multiprofessional healthcare teams. J Adv Nurs.2006; 53: $244-252$. http://dx.doi.org/10.1111/j.1365-2648.2006.03719.x

[13] Atwal A., Caldwell K. Do all health and social care professionals interact equally: a study of interactions in multiprofessional teams in the United Kingdom. Scand J Caring Sci. 2005; 19: 268-273. http://dx.doi.org/10.1111/j.1471-6712.2005.00338.x

[14] Kalisch BJ., Curley M., Stefanov S. An intervention to enhance nursing staff teamwork and engagement. JONA. 2007; 37: 77-84.

[15] Timmermans O, Van Linge R, Van Petegem P, Denekens J. Team learning and innovation in nursing teams: Results of a comprehensive research project. Journal of Nursing Education and Practice. 2012; 2: 10-21. http://dx.doi.org/10.5430/jnep.v2n4p10.

[16] Miers M., Pollard K. The role of nurses in interprofessional health and social care teams. Nursing management. 2009 ; $15: 30-35$.

[17] Parfitt B., Mughal M., Thomas H. Working together; a nursing development project in Tajikistan. International Nursing Review. 2008; 55: 205-211. http://dx.doi.org/10.1111/j.1466-7657.2007.00609.x

[18] McLellan H., Bateman H., Bailey P. The place of 360 degree appraisal within a team approach to professional development. Journal of Interprofessional Care. 2005; 19: 137 - 148. http://dx.doi.org/10.1080/13561820400024290

[19] Thomas M., Hynes C. The darker side of groups. Journal of Nursing Management. 2007; 15: 375-385. http://dx.doi.org/10.1111/j.1365-2834.2007.00697.x

[20] Liukkonen V., Virtanen P., Kivimäki M., Pentti J., Vahtera J. Social capital in working life and the health of employees. Social Science \& Medicine. 2004; 59: 2447-2458. http://dx.doi.org/10.1016/j.socscimed.2004.04.013

[21] Perry B. Role modeling excellence in clinical nursing practice. Nurse Education in Practice. 2009; 9: 36-44.

[22] Gustafsson C., Fagerberg I. Reflection, the way to professional development? J Clin Nurs. 2004; 13: 271-280. http://dx.doi.org/10.1046/j.1365-2702.2003.00880.x

[23] Salonen A.H., Kaunonen M., Meretoja R., Tarkka M-L. Competence profiles of recently registered nurses working in intensive and emergency settings. J Nursing Manag. 2007; 15: 792-800. http://dx.doi.org/10.1111/j.1365-2934.2007.00768.x

[24] Suominen T., Rankinen S., Kuokkanen L., Kukkurainen ML., Savikko N., Irvine Doran D. The constancy of work-related empowerment. J Nursing Manag. 2007; 15: 595-602. http://dx.doi.org/10.1111/j.1365-2834.2007.00735.x

[25] Hallin K., Danielson E. Registered Nurses’ perceptions of their work and professional development. J Adv Nurs. 2008 ; 61 : 62-70. http://dx.doi.org/10.1111/j.1365-2648.2007.04466.x

[26] Henderson A., Winch S. Staff development in the Australian context: Engaging with clinical contexts for successful knowledge transfer and utilization. Nurse Education in Practice. 2008; 8: 165-169. http://dx.doi.org/j.nepr.2007.04.009 
[27] O’Neil E., Cherner D., Hirschkorn C., Morjikian R., West T. Developing Nursing Leaders: An Overview of Trends and Programs. JONA. 2008; 38: 178-183. http://dx.doi.org/10.1097/01.NNA.0000312754.61170.fa

[28] Hasson H., Arnetz J. The impact of educational intervention for elderly care nurses on care recipients' and family relatives' ratings of quality of care: A prospective, controlled intervention study. IJNS. 2008; 45: 166-179. http://dx.doi.org/10.1016/j.ijnurstu.2006.09.001

[29] Cunningham D., Kelly D. Community nursing managers’ perceptions and experiences of protected learning time: a qualitative study. Qual Prim Care. 2008; 16: 39-47. PMid:18700077

[30] Johnson A, Hong H, Groth M, Parker SK. Learning and development: promoting nurses' performance and work attitudes. J Adv Nurs. 2011; 67: 609-620. http://dx.doi.org/10.1111/j.1365-2648.2010.05487.x

[31] Polit D., Beck C. Nursing Research: generating and assessing evidence for nursing practice. 9th edn. 2011. Wolters Kluwer Health/Lippincott Williams \& Wilkins, Philadelphia, USA.

[32] Elo S., Kyngäs H. The qualitative content analysis process. J Adv Nurs. 2008; 62: 107-115. http://dx.doi.org/10.1111/j.1365-2648.2007.04569.x 